\title{
Far Lateral Approach for Disconnection of Craniocervical Junction Dural Arteriovenous Fistula Presented with Myelopathy and Hydrocephalus
}

\author{
Siu Kei Samuel Lam ${ }^{1}$ Sai Lok Chu ${ }^{1}$ Shing Chau Yuen ${ }^{1}$ Kwong Yui Yam ${ }^{1}$
}

${ }^{1}$ Department of Neurosurgery, Tuen Mun Hospital, Hong Kong Special Administrative Region, Tuen Mun, Hong Kong

J Neurol Surg B 2021;82(suppl S1):S45-S47.
Address for correspondence Samuel S. K. Lam, MBChB, FRCSEd(SN), Department of Neurosurgery, Tuen Mun Hospital, Tuen Mun, Hong Kong (e-mail: csl_ginnay@yahoo.com.hk).

\begin{abstract}
We report a case of craniocervical junction dural arteriovenous fistula (dAVF) presented with myelopathy and normal pressure hydrocephalus, and was treated with hybrid approach of embolization and surgical disconnection. A 68-year-old gentleman presented with 1 year history of unsteady gait and sphincter disturbance. Magnetic resonance imaging (MRI) showed abnormally enlarged and tortuous vessels over right cerebellomedullary cistern. Digital subtraction angiogram (DSA) showed Cognard's type-V dAVF at craniocervical junction. Catheter embolization was performed via

Keywords

- dural arteriovenous fistula

- craniocervical junction

- far lateral approach

- myelopathy

- hydrocephalus external carotid artery and finally surgical disconnection was done with far lateral approach (-Fig. 1). Postoperative DSA showed no more arteriovenous shunting (-Fig. 2). Clinically the patient improved after a course of rehabilitation. Dural AVF at craniocervical junction is rare and its clinical presentation can be highly variable from subarachnoid hemorrhage to brainstem dysfunction. Identification of the exact fistula site is essential in surgical planning. Surgery is effective and safe to achieve complete obliteration and good clinical outcome. ${ }^{1-6}$

The link to the video can be found at: https://youtu.be/xl48stSIWpY.
\end{abstract}

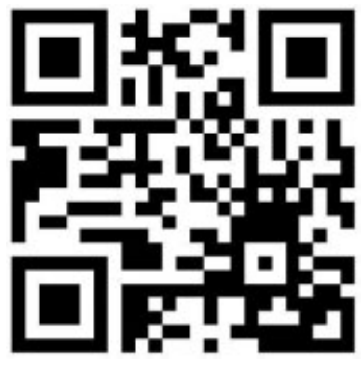

received

February 28, 2019 accepted after revision

March 8, 2020

published online

November 26, 2020

www.thieme.com/skullbasevideos

www.thieme.com/jnlsbvideos

DOI https://doi.org/ 10.1055/s-0040-1714402. ISSN 2193-6331. (c) 2020. The Author(s).

This is an open access article published by Thieme under the terms of the Creative Commons Attribution-NonDerivative-NonCommercial-License, permitting copying and reproduction so long as the original work is given appropriate credit. Contents may not be used for commercial purposes, or adapted, remixed, transformed or built upon. (https://creativecommons.org/ licenses/by-nc-nd/4.0/)

Georg Thieme Verlag KG, Rüdigerstraße 14, 70469 Stuttgart, Germany 


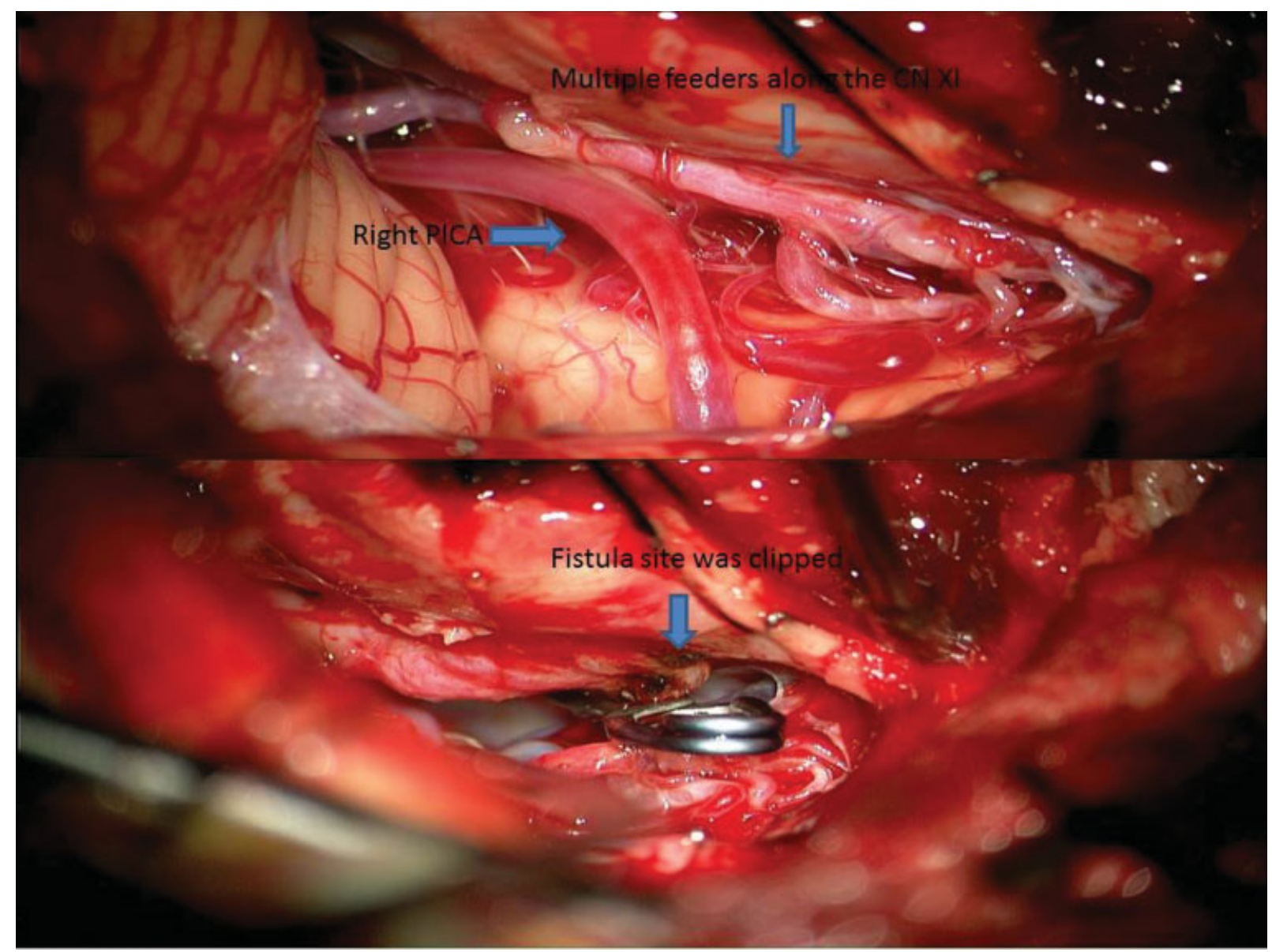

Fig. 1 Intraoperative photos showing the anatomy (upper) and the fistula site (lower).

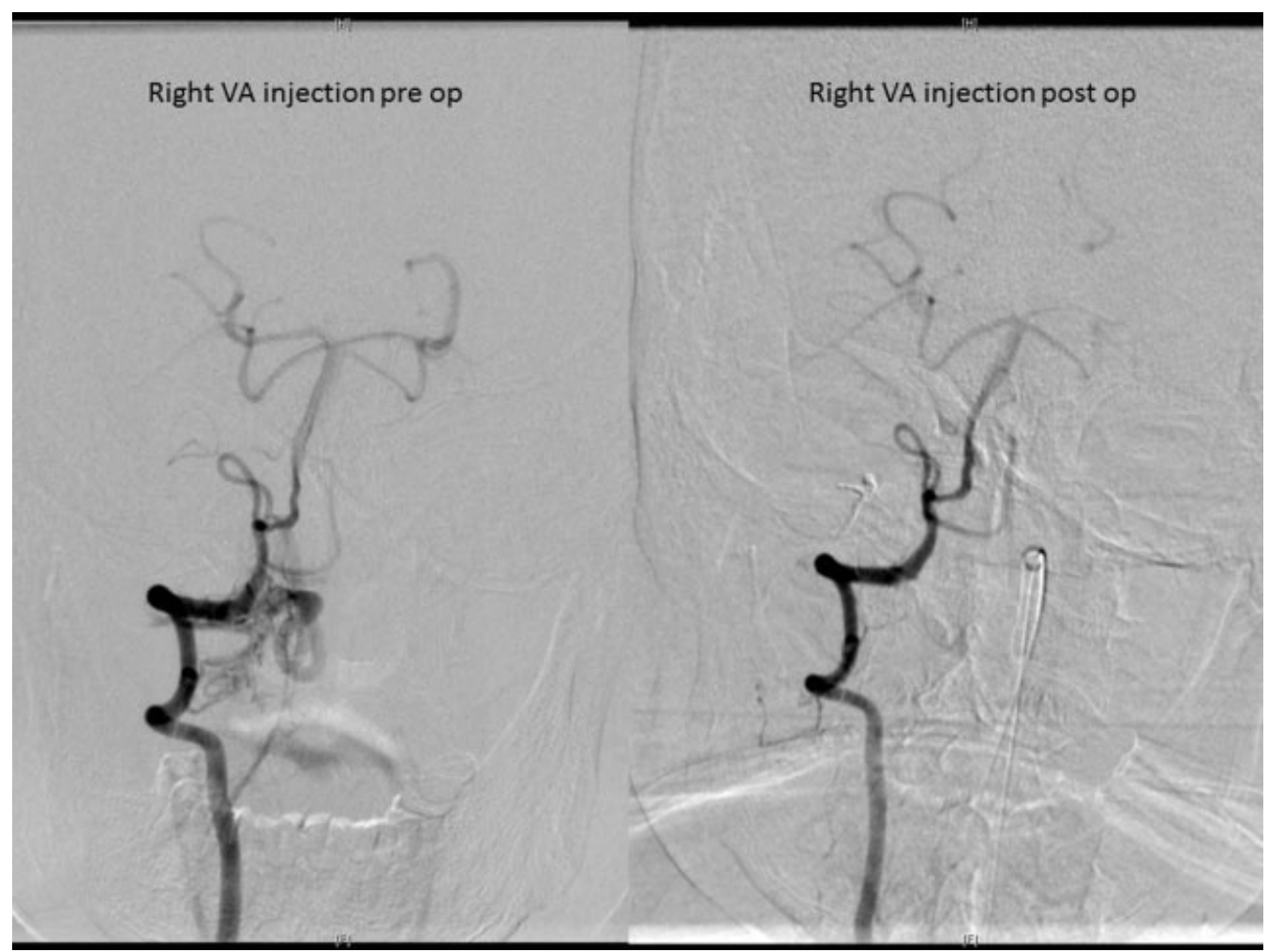

Fig. 2 Post operative DSA (right) showing complete eradication of arteriovenous shunting. 


\section{Disclosures}

The authors declare that they have no conflict of Interest.

\section{Acknowledgments}

The authors would like to thank $\mathrm{Mr}$. CK $\mathrm{Ng}$ for his intraoperative monitoring support and Dr. Jason Ho for his IT support.

\section{References}

1 Lin IC, Wu HC, Wu CH, Lin WC, Lieu AS. Craniocervical junction spinal dural arteriovenous fistula presenting with progressive myelopathy and sudden deterioration. Formos J Surg 2017; 50:223-226

2 Hacein-Bey L, Konstas AA, Pile-Spellman J. Natural history, current concepts, classification, factors impacting endo- vascular therapy, and pathophysiology of cerebral and spinal dural arteriovenous fistulas. Clin Neurol Neurosurg 2014; 121:64-75

3 Nakahara Y, Ogata A, Takase Y, et al. Treatment of dural arteriovenous fistula presenting as typical symptoms of hydrocephalus caused by venous congestion: case report. Neurol Med Chir (Tokyo) 2011;51:229-232

4 Ruiz-Juretschke F, Perez-Calvo JM, Castro E, et al. A single-center, long-term study of spinal dural arteriovenous fistulas with multidisciplinary treatment. J Clin Neurosci 2011;18(12): 1662-1666

5 Wang JY, Molenda J, Bydon A, et al. Natural history and treatment of craniocervical junction dural arteriovenous fistulas. J Clin Neurosci 2015;22(11):1701-1707

6 Zhao J, Xu F, Ren J, Manjila S, Bambakidis NC. Dural arteriovenous fistulas at the craniocervical junction: a systematic review. J Neurointerv Surg 2016;8(06):648-653 